\title{
The Potential Influence of Tree Crown Structure on the Ginkgo Harvest
}

\author{
Yan Xuan, Linyun Xu*, Guanhua Liu and Jie Zhou \\ College of Mechanical and Electronic Engineering, Nanjing Forestry University, Nanjing 210037, China; \\ xuany@njfu.edu.cn (Y.X.); njfughliu@gmail.com (G.L.); jiezhou@njfu.edu.cn (J.Z.) \\ * Correspondence: lyxu@njfu.edu.cn
}

check for

updates

Citation: Xuan, Y.; Xu, L.; Liu, G.; Zhou, J. The Potential Influence of Tree Crown Structure on the Ginkgo Harvest. Forests 2021, 12, 366. https://doi.org/10.3390/f12030366

Academic Editor: H. Roaki Ishii

Received: 5 February 2021

Accepted: 17 March 2021

Published: 19 March 2021

Publisher's Note: MDPI stays neutral with regard to jurisdictional claims in published maps and institutional affiliations.

Copyright: (C) 2021 by the authors. Licensee MDPI, Basel, Switzerland. This article is an open access article distributed under the terms and conditions of the Creative Commons Attribution (CC BY) license (https:/ / creativecommons.org/licenses/by/ $4.0 /)$.
Abstract: Ginkgo biloba L. has significant health benefits and considerable economic value, but harvesting the fruit is highly labor-intensive. Mechanical vibration harvesting has been shown effective in harvesting various fruit types. In the study of vibration harvesting, the research on the vibration characteristics of fruit trees focuses on the natural frequency (resonance frequency), model, and damping coefficient, which are the main factors affecting the vibration characteristics of trees. But field harvesting experiments have shown that the tree structure may have an impact on the vibration characteristics of the fruit tree and the efficiency of mechanical harvesting. In addition, the research on the damping coefficient of fruit trees is mainly low-frequency damping, and the relevant results cannot be applied to the actual vibration harvesting frequency range. Applying a natural frequency with low damping coefficient to excite a tree can reduce additional energy dissipation. This study explored the influence of ginkgo crown structure on the vibration characteristics and the law of damping changes with frequency. After counting 273 ginkgo trees, two typical ginkgo crown structures, monopodial branching and sympodial branching, were selected to be analyzed for vibration spectrum and damping coefficient. The vibration models for different crown-shaped ginkgo trees were simulated to analyze the vibration state at different frequencies. For sympodial branching ginkgo trees, the consistency of natural frequencies at different branches was better than monopodial branching ginkgo trees. The finite element model analysis shows that monopodial branching ginkgo trees have mainly partial vibrations at different branches when vibrating at high frequencies. The high-frequency vibrations in sympodial branching reflect the better overall vibration of the canopy. The damping coefficients for the two crown types decreased with the increase in frequency. The monopodial branching damping coefficient was $0.0148-0.0298$, and the sympodial branching damping coefficient was slightly smaller at 0.0139-0.0248. Based on the test results, the sympodial branching ginkgo tree has better vibration characteristics. The results indicate that controlling the crown structure of fruit trees to be sympodial branching by pruning may help improve the overall vibration characteristics of fruit trees.

Keywords: natural frequency; model simulation analysis; damping coefficient; vibration harvest

\section{Introduction}

Ginkgo biloba is an important economic crop in China and is widely used in the food and medical industries for its rich medicinal value and nutrition [1-5]. Given its rising popularity in recent years, China's ginkgo industry has reached 1.2 billion hectares in the planting area and accounts for $90 \%$ of world production [6-8]. However, much of the industry's primary harvesting method remains labor-intensive and time-consuming, with production costs accounting for $35 \%$ to $45 \%$ in the entire production process [9]. Developing an efficient and economical harvesting techniques is therefore critical in order to maintain the ginkgo industry's development in an economically sustainable way.

Previous studies have shown that mechanical harvesting based on resonance-vibration technology is an efficient technique that can improve harvesting efficiency and reduce 
costs [10-12]. At present, the primary research focus has been on the effect of the vibration method and vibration parameters on fruit drop rate and fruit damage rate [13-18]. Research has shown that the crown structure of fruit trees is a major factor affecting fruit harvesting [19-21]. A suitable crown structure is conducive to vibration of the tree during mechanical harvesting, which improves harvesting efficiency. Castro-Garcia et al. [22,23] studied the impact of the vibration position on harvest efficiency during the vibration harvest. The study found that the olives located at the top, outside of the canopy, accounted for more than $60 \%$ of the entire harvest. However, the olives from the inside and the bottom of the canopy had small size, low economic value, and low oil content, and were difficult to harvest. The study suggests that modifying the structure of the fruit tree to suit the harvesting machine by pruning would increase yield. Shamshiri et al. [24] studied vibration harvesting of citrus. Their results showed that the branch vibration harvesting technique in the form of direct movement of the branches is the most effective citrus harvesting method. The results of the field citrus harvest experiment showed the vibration recovery rate was as high as $90 \%$. However, they suggested that the crown structure of fruit trees should be considered to adapt to the working method of harvesting machinery to improve harvest efficiency. Xu et al. [25-27] conducted a number of studies on the vibration of fruit trees. In the indoor vibration tests of ginkgo trees, the natural vibration characteristics and forced vibration response were found to be consistent at some frequencies when comparing the vibration spectrum curve of fruit trees and the vibration response. Their studies also found fruit trees with different crown structures had different forced vibration response. However, many researchers mainly studied the vibration characteristics of one type of crown, and did not compare different crown structures at the same time. Research on the vibration characteristics of fruit trees with different crown structures was insufficient.

Vibration harvesting based on the resonance method can cause the overall response of the fruit tree to achieve the effect of vibration harvesting. The selection of vibration harvesting frequency requires further research on the natural frequency of fruit trees. He [28] proposed a method to effectively obtain natural frequencies through sweep frequency experiments. The results show that the identified frequency can be regarded as the optimal vibration frequency of adaptive vibration. Xuan et al. [29] studied the regulations between vibration frequency and the tree's response under external excitation. The acceleration response of the tree under the excitation of four natural frequencies and four non-natural frequencies was tested. The results showed that the acceleration response of the ginkgo tree under natural frequency excitation is greater than the vibration under non-natural frequency. However, selecting a specific harvesting frequency would be difficult because there are a large number of natural frequencies obtained by the vibration spectrum. The fruit tree harvesting frequency requires that the whole fruit tree has a strong response. To determine the response status of fruit trees, it is necessary to test the vibration model. But due to the complexity of the tree's structure, testing the vibration model would be difficult to achieve using the experimental method.

In recent years, the modal analysis of fruit trees by the finite element method (FEM) has been used to obtain the vibration characteristics of fruit trees [30,31]. Using laser scanning technology, Jackson et al. [32] established a finite element model of tree wind vibration through point cloud data and quantitative structure model. The strain distribution of trees under wind vibration was obtained through numerical simulation, which was analogical compared with measured strain. The results suggested that the fruit tree model constructed by the laser point cloud information was very similar to the actual fruit tree and that tree vibration can be analyzed using finite element models. Xu et al. [33] proposed a fast modeling method for fruit trees with spatial 6-degrees of freedom beam elements, which combines laser scanning with finite element theory. The characteristic of this model is that it calculates the mass of fruits and leaves per unit length of ginkgo tree branches to obtain its distribution law, and adds the mass of leaves and fruits to the corresponding unit nodes to make the model more accurate. Wang Dong et al. [34] constructed three finite element models for cherry trees with different crown shapes. They found that different tree types 
are suitable for different excitation methods, which, to some extent, shows the effect of crown structure on the vibration characteristics of fruit trees.

There may be more than one harvesting frequency suitable for a fruit tree $[26,28]$, which can be further selected according to the different damping characteristics. The damping of the fruit tree is the energy dissipation capacity for external excitation, such as wind vibration excitation and mechanical excitation. Studies on traditional damping have mainly focused on the tree's wind resistance [35]. However, research on the damping changes of fruit trees with frequency has been insufficient. If the fruit tree's damping coefficient has a certain regulation, the frequency range with smaller damping characteristics of the fruit tree can be selected, which may help improve the harvest efficiency. Natural frequency, model, and damping coefficient are the main factors that reflect the vibration characteristics of fruit trees. Studies on the three would be helpful in the development and progress of vibration harvesting technology.

The study explored the influence of the crown structure of fruit trees on vibration characteristics. Knowing the vibration characteristics of fruit trees with different crown structures can help stakeholders determine and select tree structures more conducive to vibration harvesting. The finite element calculation method was used to explore the different crown-shaped ginkgo vibration models showing the vibration magnitude at different branches. The changing trend of the damping coefficient was also studied to determine suitable frequencies with minimal damping. Less damping would mean stronger fruit tree vibrations and less mechanical energy dissipation. The conclusions and recommendations of this study can be used as reference to further improve the efficiency of vibration harvesting in fruit trees.

\section{Materials and Methods}

\subsection{Test Tree}

The shape of fruit trees can be divided into two main groups: the monopodial branching and sympodial branching. Under a natural growth environment, ginkgo is mainly a monopodial branching fruit tree. In this study, we first surveyed the Nanjing Forestry University $\left(32.1^{\circ} \mathrm{N}, 118.8^{\circ} \mathrm{E}\right.$, Nanjing, China) to examine the available tree stock. The 273 ginkgo trees surveyed were divided into two categories: natural growth without artificial pruning and artificial construction. The survey results showed that almost all ginkgo trees in their natural growth state have monopodial branching (Figure 1a), while approximately $90 \%$ of artificially constructed ginkgo trees have Y-shaped sympodial branching (Figure $1 \mathrm{~b}$ ). This means monopodial and Y-shaped sympodial branching types are representative ginkgo tree crown structures. In this study, we selected two typical structures, the monopodial branching and the Y-shaped sympodial branching structures, to study the vibration characteristics of ginkgo trees with different canopy structure.

Considering potential factors affecting the vibration characteristics of the tree, testing trees had to be selected with similar age, similar size, and growing up in the same environment. After excluding other vibration-affecting factors, the differences in the vibration characteristics of the sample trees can be assumed to be almost caused by the difference of crown structure. Three monopodial branching trees (sample 1, sample 2, sample 3) and three Y-shaped sympodial branching trees (sample 4, sample 5, sample 6) were selected. A total of six ginkgo trees were tested in the laboratory with the ginkgo trees clamped on the ground by using a vise firmly fixed. The test period was in January 2019, and the entire test was completed within one day after the fruit trees were cut. 


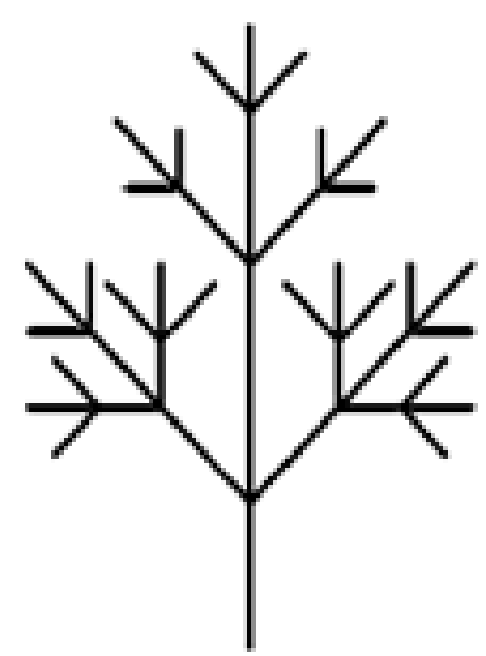

(a)

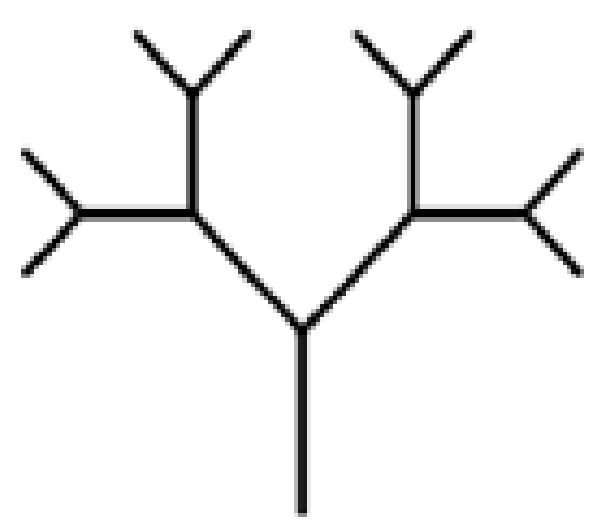

(b)

Figure 1. Branching type of trees with the (a) monopodial branching and (b) sympodial branching.

When executing vibration tests in fruit trees, the sensor must be properly positioned on both the branches and the trunk to obtain more tree vibration characteristics. In this study, four sensor points were arranged on each test tree. In each of the six trunks, a point was selected and was labeled as Point A. For monopodial branching trees, four main branches were marked Points B, C, D, and E (Figure 2a). For Y-shaped sympodial branching trees, two in each of the Y-shaped branches were selected and marked as Points $B_{1}, B_{2}, C_{1}$, and $\mathrm{C}_{2}$ (Figure $2 \mathrm{~b}$ ).

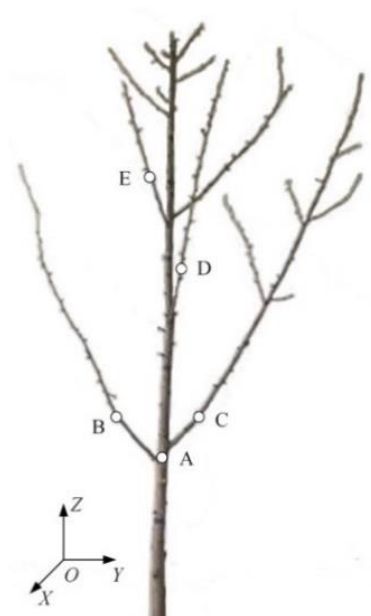

(a)

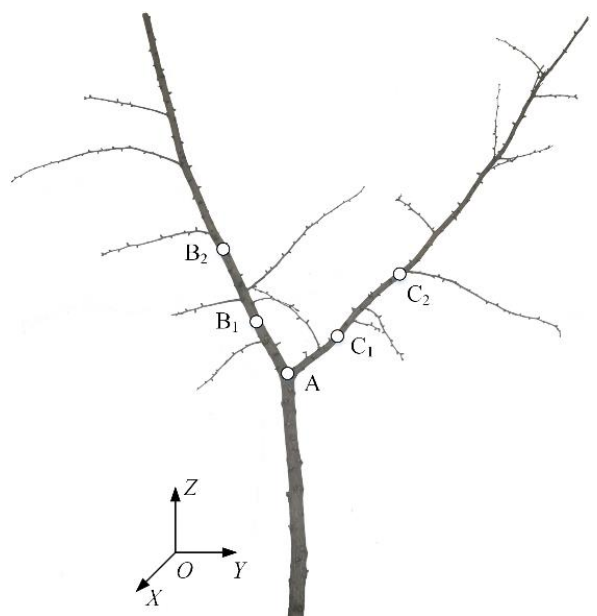

(b)

Figure 2. Test objects with (a) one of the three monopodial branching testing trees, (b) one of the three Y-shaped sympodial branching testing trees.

\subsection{Tree Parameters}

In order to describe the size of the test fruit tree more accurately, the experiment's coordinate system had to be first established. The Z-axis lies along the direction of the main trunk growth, while the $X-Y$ plane is perpendicular to the $Z$-axis. Suppose that the branches of the ginkgo tree have an ideal circular cross-section. The size of the trees and the diameter parameter of the measuring points were measured and tabulated, as summarized in Tables 1 and 2. 
Table 1. Monopodial branching tree parameters.

\begin{tabular}{|c|c|c|c|c|c|c|c|c|c|}
\hline \multirow{2}{*}{$\begin{array}{l}\text { Sample } \\
\text { Number }\end{array}$} & \multirow{2}{*}{$\begin{array}{l}\text { Height of } \\
\text { Tree/mm }\end{array}$} & \multirow{2}{*}{$\begin{array}{l}\text { Width of } \\
\text { Crown/mm }\end{array}$} & \multirow{2}{*}{$\begin{array}{c}\text { Trunk } \\
\text { Diameter/mm }\end{array}$} & \multirow{2}{*}{$\begin{array}{c}\text { Number of } \\
\text { Mean Segments }\end{array}$} & \multicolumn{5}{|c|}{ Point Diameter/mm } \\
\hline & & & & & $\mathbf{A}$ & B & $\mathrm{C}$ & $\mathbf{D}$ & E \\
\hline Tree 1 & 2362 & 1523 & 45.1 & 9 & 40.3 & 13.4 & 16.6 & 9.9 & 9.1 \\
\hline Tree 2 & 2236 & 1435 & 43.5 & 8 & 37.3 & 16.2 & 11.5 & 10.8 & 8.9 \\
\hline Tree 3 & 2281 & 1682 & 51.4 & 6 & 42.6 & 19.3 & 17.5 & 12.6 & 14.2 \\
\hline
\end{tabular}

Table 2. Sympodial branching tree parameters.

\begin{tabular}{|c|c|c|c|c|c|c|c|c|c|}
\hline \multirow{2}{*}{$\begin{array}{l}\text { Sample } \\
\text { Number }\end{array}$} & \multirow{2}{*}{$\begin{array}{l}\text { Height of } \\
\text { Tree/mm }\end{array}$} & \multirow{2}{*}{$\begin{array}{c}\text { Width of } \\
\text { Crown } / \mathrm{mm}\end{array}$} & \multirow{2}{*}{$\begin{array}{c}\text { Trunk } \\
\text { Diameter/mm }\end{array}$} & \multirow{2}{*}{$\begin{array}{c}\text { Number of } \\
\text { Mean Segments }\end{array}$} & \multicolumn{5}{|c|}{ Point Diameter/mm } \\
\hline & & & & & A & B & $\mathrm{C}$ & D & $\mathbf{E}$ \\
\hline Tree 4 & 2463 & 2127 & 49.8 & 2 & 41.2 & 36.2 & 34.5 & 24.6 & 21.8 \\
\hline Tree 5 & 2416 & 2321 & 46.7 & 2 & 38.6 & 30.2 & 28.5 & 29.3 & 27.2 \\
\hline Tree 6 & 2385 & 2265 & 51.6 & 2 & 45.3 & 34.4 & 32.3 & 30.3 & 28.6 \\
\hline
\end{tabular}

\subsection{Vibration Characteristic Test Method}

The transient excitation method employs a pulse force using a force hammer and measures the impulse response of the measured object to obtain the spectrum function. For trees, the vibration spectral characteristics can generally be obtained with an excitation pulse, and the signals are then detected using multiple acceleration sensors [36]. However, this approach has two major disadvantages. First, for branches with less stiffness (i.e., rigidity), the additional weight of the sensor would affect the accuracy of the spectral testing results. Second, the sensor has to be moved to different positions, which results in an inefficient system. In order to overcome these shortcomings, the methodology was modified based on the Maxwell dissimilarity assumption.

As per the Maxwell dissimilarity hypothesis, the point $k$ response caused by the excitation at $j$ is equal to the point $j$ response caused by the excitation at $k$ (as shown in Figure 3). The transfer function satisfies $H_{j}^{k}=H_{k}^{j}$.

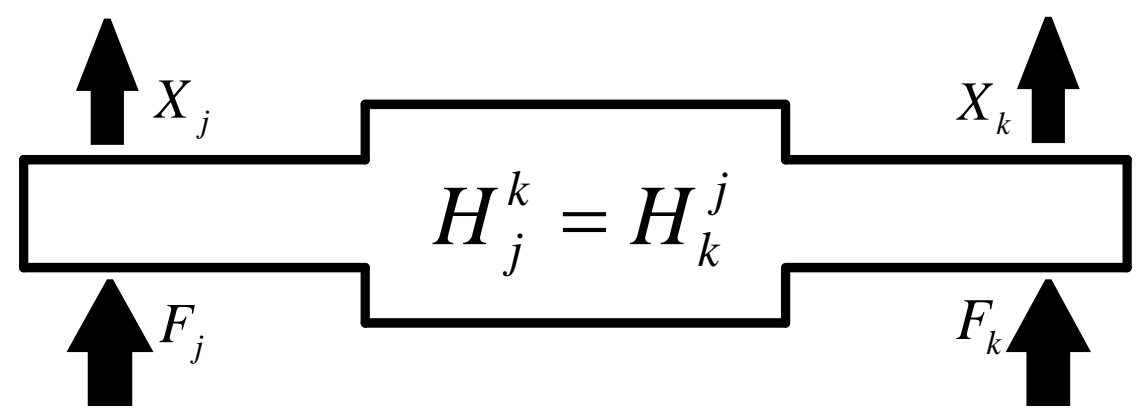

Figure 3. Schematic diagram of the anisotropy.

In the experiment, a triple-axis acceleration sensor was affixed at point A. Each measuring point was tapped to determine the transfer function, and the results were used to obtain the resonance frequency for the tree. The test devices included an impact hammer (LC-02A, Jiangsu Sinocera Piezotronics Inc., Yangzhou, China), four triple-axis accelerometers (CA-YD-141, Jiangsu Sinocera Piezotronics Inc., Yangzhou, China), two charge amplifiers (YE5853A, Jiangsu Sinocera Piezotronics Inc., Yangzhou, China), three data acquisition units (NI cDAQ-9174, the National Instrument Co., Ltd., Austin, TX, USA), and analysis software (CRAS V7.1, The First Test Software Engineering, Co., Ltd., Nanjing, China). The $X Y Z$ direction of the triple-axis accelerometer installation was made consistent with the $X Y Z$ coordinate system. The direction of the hammer strike was always the same as the $\mathrm{X}$-direction of the coordinate system. 


\subsection{Modal Parameter Identification Method}

According to the theory of mechanical vibration, assuming that the tree is a multidegree of freedom system with viscous damping, the modal frequency response function of the tree can be expressed as:

$$
H(\omega)=\sum_{i=1}^{\mathrm{n}} \frac{\varphi_{i} \varphi_{i}^{T}}{k_{i}-\omega^{2} m_{i}+j \omega c_{i}}
$$

where $\omega_{i}$ is the $i$-th mode shape, $\mathrm{rad} ; m_{i}$ is the $i$-th modal quality, $\mathrm{Kg} ; k_{i} k_{i}$ is the $i$-th modal stiffness, $\mathrm{N} / \mathrm{m}$; and, $c_{i}$ is the $i$-th mode viscous proportional damping coefficient.

When the excitation frequency $\omega$ is near a certain modal frequency $\omega_{i}$, the modal mode plays a leading role, and the frequency response function values of the other modes have little effect on the tree response at this time. Equation (1) can be simplified to:

$$
H(\omega)=\frac{\varphi_{i} \varphi_{i}^{T}}{k_{i}-\omega^{2} m_{i}+j \omega c_{i}}
$$

Equation (2) can then be decomposed into an expression composed of real and virtual parts:

$$
H(\omega)=H^{R}(\omega)+j H^{I}(\omega)
$$

The real and virtual frequency characteristic curves corresponding to a certain modal frequency are shown in Figure 4.

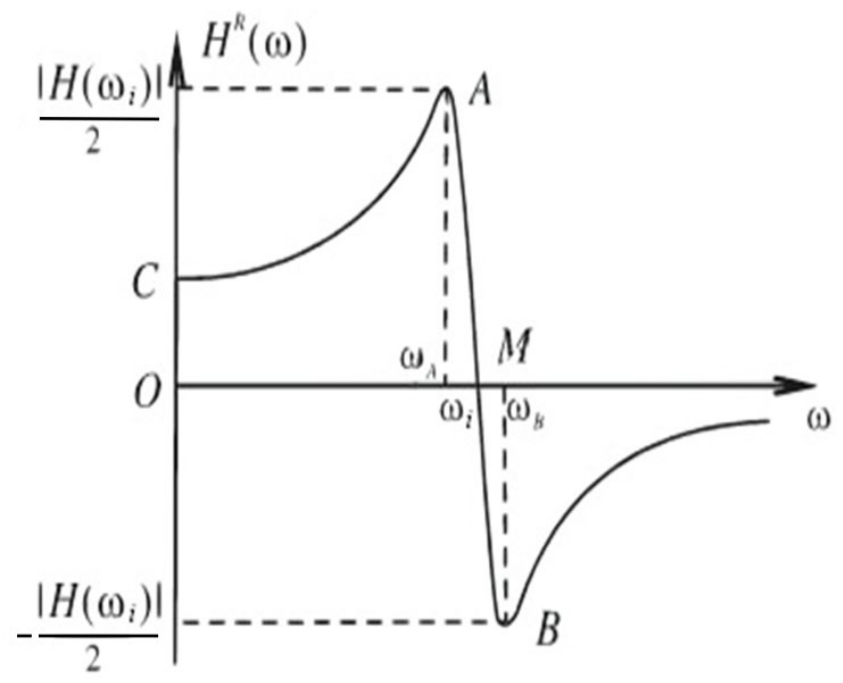

(a)

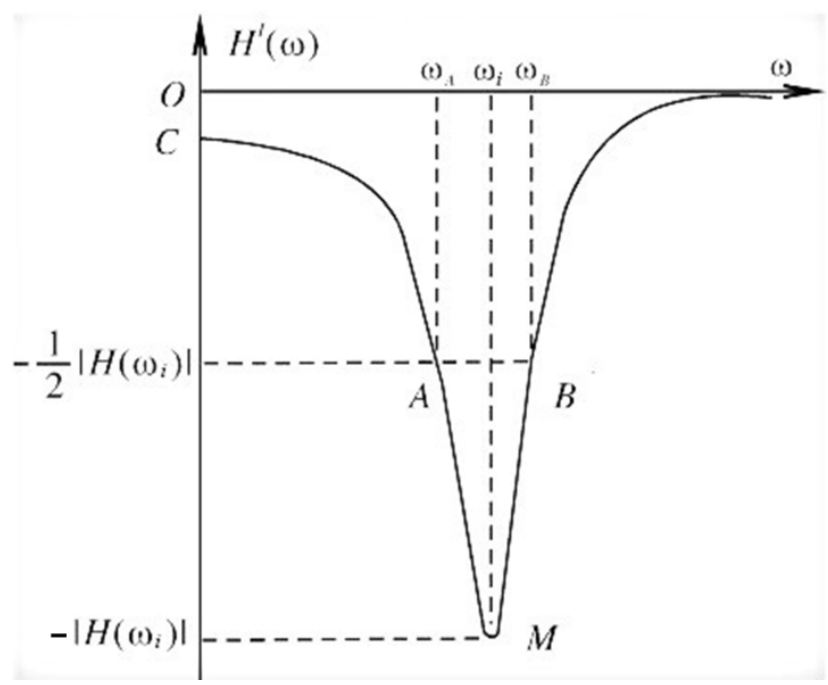

(b)

Figure 4. Characteristic curve of displacement frequency response function of the viscous damping with the (a) real frequency and $(\mathbf{b})$ virtual frequency.

The real and imaginary frequency diagrams can then be used to confirm the modal frequency and the damping ratio. The modal frequency $\omega_{i}$ is determined by the frequency corresponding to the high amplitude in the real frequency characteristic curve (Figure 4a), or the frequency corresponding to the lowest (valley) value in the imaginary frequency characteristic curve (Figure $4 \mathrm{~b}$ ). The damping ratio can be determined by the half-power bandwidth $\Delta \omega_{i}$. The $i$-th order damping ratio coefficient $\zeta_{i}$ can be calculated from the imaginary frequency characteristic curve:

$$
\zeta_{i}=\frac{\Delta \omega_{i}}{2 \omega_{i}}=\frac{\omega_{B i}-\omega_{A i}}{2 \omega_{i}}
$$


In the evaluation of the frequency response function, the signal in the $Y$-direction consistent with the impact force was selected for analysis. The reasons for the selection are as follows: (1) As long as the excitation point has enough energy to excite, the impact would be able to completely agitate the various modes in the system. In this study, the hammer was swung along the X-direction, and the excitation energy is largest in this direction. The corresponding acceleration response at the $X$-direction is also the strongest. (2) In a previous study, no significant difference was found in the natural frequencies of two orthogonal directions along the vertical plane of the tree trunk growth direction [37]. (3) A preliminary test using the pull-release method was conducted to examine the fundamental frequency and damping coefficient in the $X$ - and $Y$-directions. The results showed the fundamental frequency was consistent, and the difference in the damping coefficients did not exceed $5 \%$ between the $X$ - and $Y$-directions.

\subsection{Model Reconstruction Method}

In this study, two-dimensional Lidar was used to scan each tree and obtain the skeleton point cloud data. The test devices (Figure 5) included a laser scanner (UTM-30LX), a $2.5 \mathrm{~m}$ slide guide (FLS40L100010C7), a stepper motor and a stepper motor driver, a programmable automation controller, a 24 V DC power supply, and Visual Studio software (Visual Studio 2018, Microsoft Corporation, Redmond, DC, USA). The laser scanning method was used for generating the three-dimensional solid model of the experimental tree [33]. This method connects two adjacent topological skeleton points by a 6-degree-of-freedom space beam element. The skeleton points of the tree were extracted from the laser-scanning point cloud. In order to improve the calculation accuracy, the model construction procedure was modified.

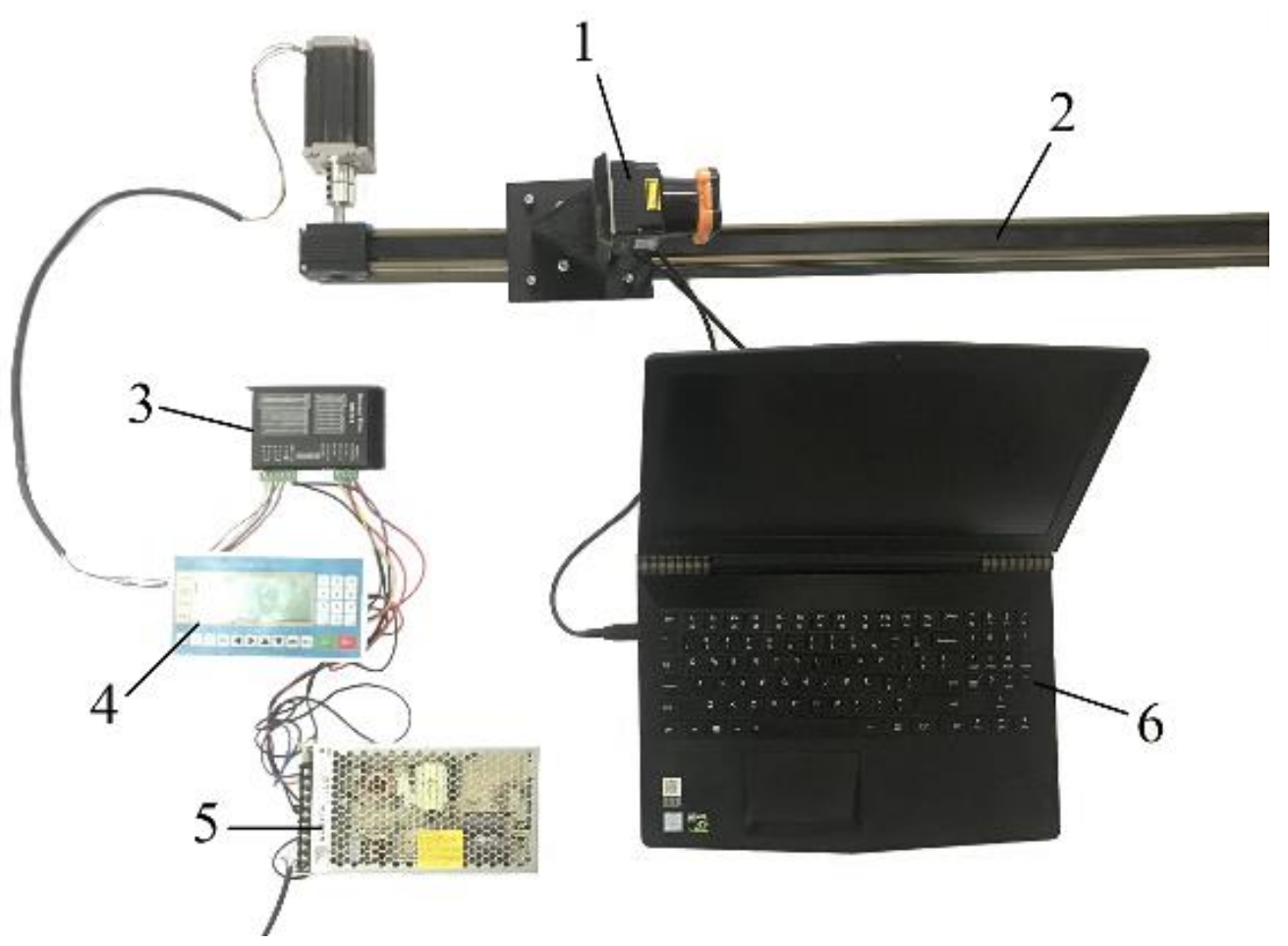

Figure 5. Laser point cloud scanning system. 1. Laser scanner. 2. Slide guide. 3. Stepper motor driver. 4. Programmable automation controller. 5. 24 V DC power supply. 6. PC.

Under the assumption that the branch section is circular, the diameter of each branch was measured by vernier calipers. The extracted space skeleton points were used to generate the tree's 3D skeleton lines in Pro-E [34]. Using the 3D skeleton lines as guide curve and the measured branch diameter for the thickness of the circular cross-section, the tree models were drawn using the sweep function in Pro-E. As shown in Figure 4, some 
branches were not reconstructed in the generated 3D models because their diameters were very thin (less than $10 \mathrm{~mm}$ ). Since constructing a three-dimensional model is laborious, only one tree for each tree type was reconstructed for simulation analysis. The two reconstructed tree models generated in Pro-E are shown in Figure 6.

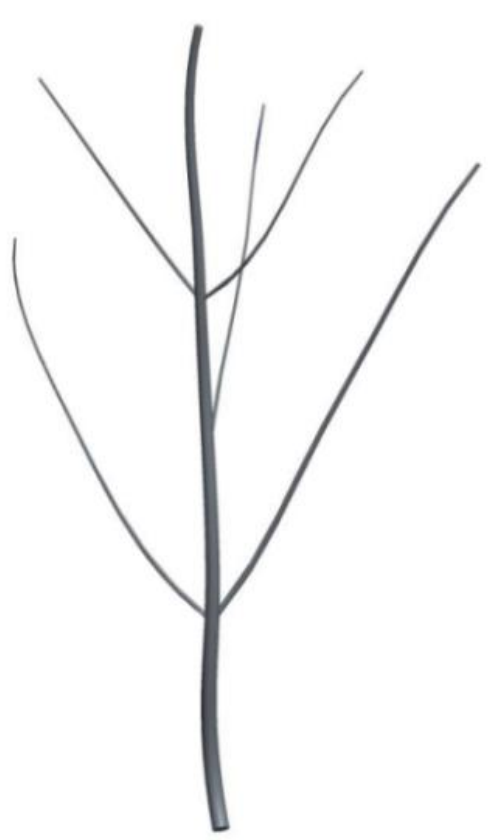

(a)

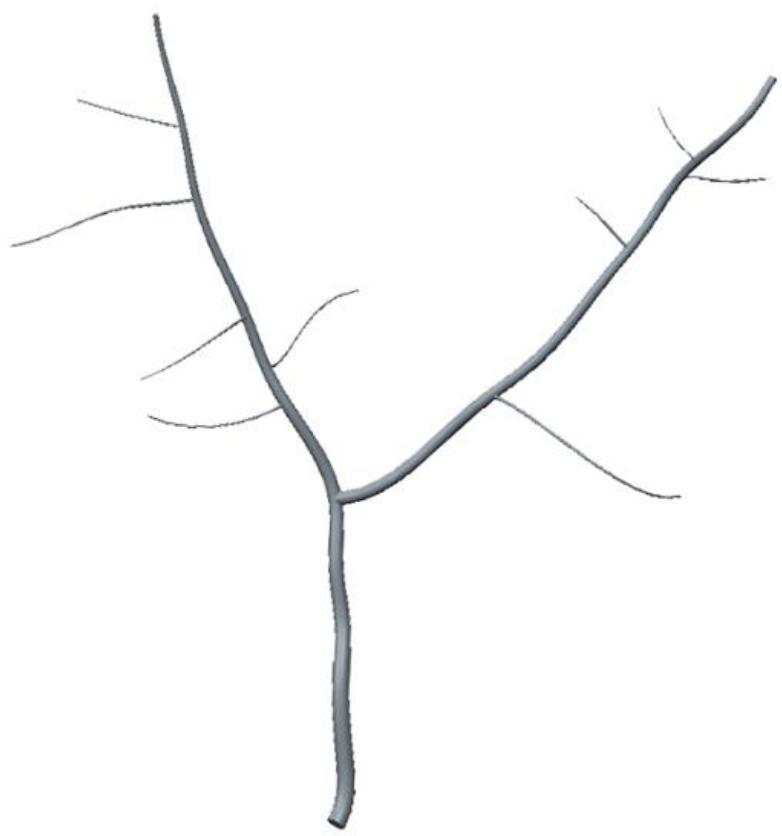

(b)

Figure 6. Two ginkgo tree models created in Pro-E with the (a) monopodial branching sample model and (b) Y-shaped sympodial branching sample model.

\subsection{Finite Element Models}

ANSYS software (ANSYS 19.0, ANSYS, Inc., Canonsburg, PA, USA) was used to simulate the tree's natural frequencies. In order to build the finite element model, the geometries created in Pro-E were imported into ANSYS and meshed using 185 solid-type elements. The orthotropic features of wood were neglected to reduce the complexity of the tree system [38]. The values of ginkgo wood density $(\rho)$, elasticity (E), and Poisson's ratio $(\mu)$ were taken from previous studies [33]. The anchoring effect of the roots in fruit trees cannot be ignored, particularly the soil and roots' dissipated vibration energy. However, the natural frequency of fruit trees is mainly influenced by the quality and stiffness of the branches. In contrast, damping has little effect on the natural frequency. In this study, fixed-end boundary conditions were applied to the bottom of the tree, which are consistent with the actual experimental boundary conditions [39]. Table 3 provides a summary of the simulation material properties applied in this study.

Table 3. Simulation material properties.

\begin{tabular}{ccccc}
\hline Property Name & Density $\left(\mathbf{k g} / \mathbf{m}^{\mathbf{3}}\right)$ & Young's Modulus (MPa) & Poisson Ratio & Shear Modulus (MPa) \\
\hline Calculated value & 1250 & 4713.9 & 0.3 & 1813 \\
\hline
\end{tabular}

\section{Results and Discussion}

\subsection{Frequency Spectrum Characteristics \\ 3.1.1. Monopodial Branching}

After filtering the accelerometer signal at the measuring point of the tree and performing Fourier transformation, the vibration spectrum curve of the test ginkgo tree was obtained. The spectral characteristics for the different tapping positions on the branches 
of the monopodial tree are shown in Figure 7. Judging from the generated vibration spectrum curve, since different side branches of the same fruit tree did not have exactly the same vibration characteristics, producing a strong vibration response for the monopodial branching fruit tree would be difficult under the excitation of a single frequency. This point is consistent with the conclusions of numerous researchers. To make the fruit tree produce a strong vibration response, a non-single-frequency excitation would have to be applied. $\mathrm{He}$ [28] adopted sweeping frequency excitation for vibration harvesting; San [40] adopted a double eccentric block vibration device with phase difference.

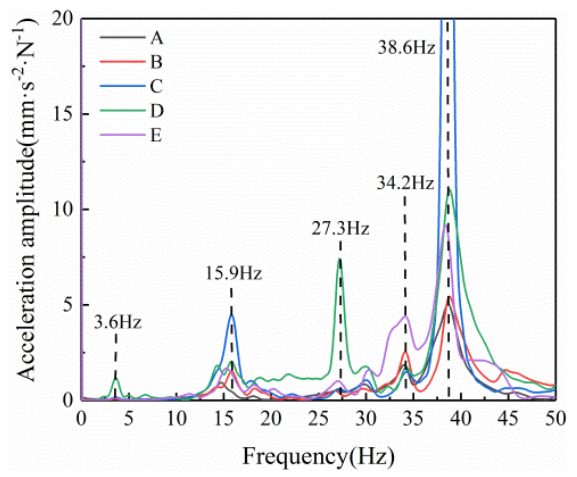

(a)

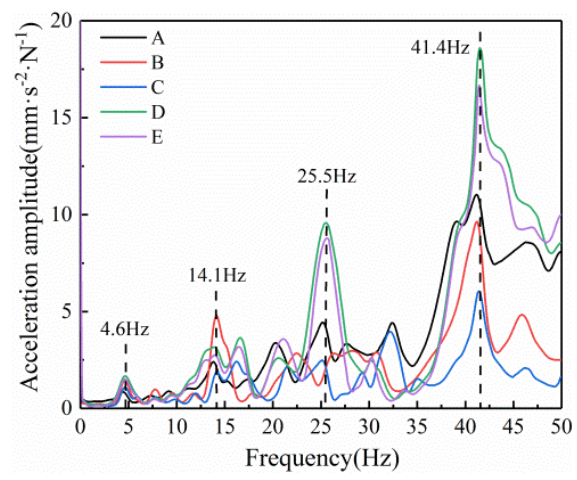

(b)

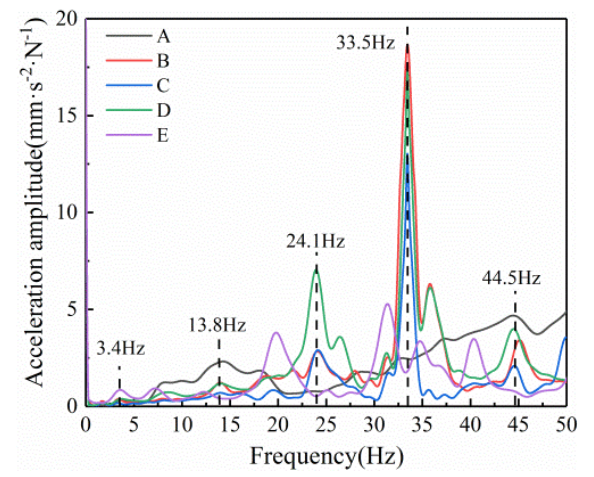

(c)

Figure 7. Spectrum curve of different measuring points in monopodial branching ginkgo trees with (a) tree $1,(\mathbf{b})$ tree 2 , and (c) tree 3 .

Multifrequency excitation can cause strong vibrations in fruit trees. However, mechanical excitation bandwidth is limited, and the actual excitation range needs to be determined before the fruit tree is excited. Therefore, some consistent frequencies for monopodial trees has to be determined from the different vibration characteristics of different side branches. The fundamental frequencies for Samples 1, 2, and 3 were $3.6 \mathrm{~Hz}, 4.6 \mathrm{~Hz}$, and $3.4 \mathrm{~Hz}$, respectively, all below $5 \mathrm{~Hz}$. The base frequency for fruit trees is much smaller than for metal components due to their soft wood material. Between 10 and $20 \mathrm{~Hz}$, there was a significant acceleration peak in the vibration spectrum of the three ginkgo trees. This peak was around $15 \mathrm{~Hz}$, which is about 3 to 4 times the base frequency. Note that there were no other acceleration peaks in the spectrum curve between 10 and $20 \mathrm{~Hz}$. According to De Langre [41], the low and concentrated natural frequencies are due to the stiffness and the flexibility of slender branches. The experimental results also show that the ginkgo tree vibration spectrum has many acceleration peaks, even if the vast majority of acceleration peaks do not have high amplitude.

In all three test samples, there was a natural frequency with high acceleration amplitude near $25 \mathrm{~Hz}$. Within 0 to $50 \mathrm{~Hz}$, the maximum frequency of the acceleration amplitude for the entire spectrum curve occurs after $30 \mathrm{~Hz}$. Acceleration amplitudes at this typical frequency were significantly higher than the acceleration amplitudes at other frequencies, which means they can easily be identified throughout the spectrum curve. The maximum acceleration in the three sample trees was above $30 \mathrm{~Hz}$, indicating that the vibration frequency most likely to cause the fruit tree to vibrate strongly is greater than $30 \mathrm{~Hz}$. However, high-frequency vibration can easily cause bark damage, and should therefore be avoided. The two frequencies with significant acceleration amplitudes can be found within 10 to $25 \mathrm{~Hz}$.

Overall, the vibration spectrum difference between the different measuring points of the monopodial branching tree is easily recognizable. Ginkgo trees have many natural frequencies within 0 to $50 \mathrm{~Hz}$, but the number of natural frequencies with significant acceleration amplitudes is about 4 to 5 . The monopodial branching ginkgo tree had an inherent frequency with a high acceleration amplitude after $30 \mathrm{~Hz}$, indicating that the optimal vibration frequency for monopodial branches is above $30 \mathrm{~Hz}$. In the general 
vibration range between 10 and $25 \mathrm{~Hz}$, one or two distinct natural frequencies can be used to make the tree respond heavily.

\subsubsection{Y-Shaped Sympodial Branching}

As shown in Figure 8, there is a significant difference in the vibration spectrum curve of the Y-shaped sympodial branching tree and the monopodial branching tree. The number of natural frequencies in Y-type sympodial branching trees within 0 to $50 \mathrm{~Hz}$ is relatively small. The natural frequency acceleration amplitude is high. Also, the consistency of the natural frequency of the spectrum curve for different measuring points of the same tree is high. The fundamental frequencies of the three Y-shaped fruit trees were $2.3 \mathrm{~Hz}$, $1.3 \mathrm{~Hz}$, and $2.6 \mathrm{~Hz}$. For both Y-shaped sympodial and monopodial branching trees, the fundamental frequencies are both below $5 \mathrm{~Hz}$, which suggests that the crown structure has little effect on the tree's fundamental frequency. The fundamental frequency of fruit trees may be related mainly to the biological morphology and wood characteristics.

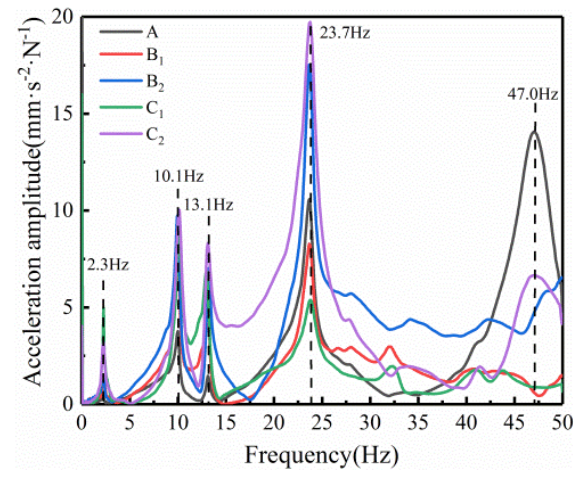

(a)

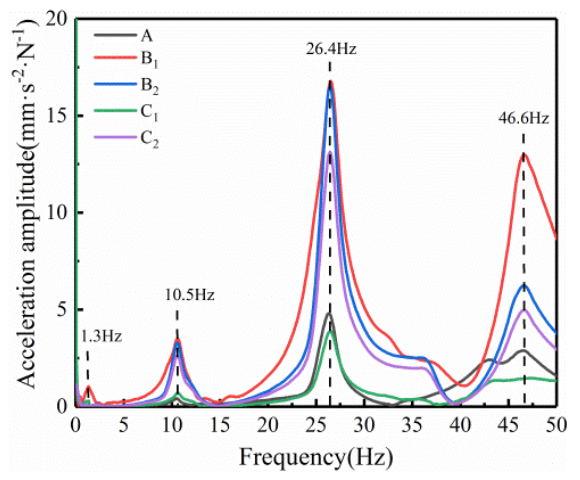

(b)

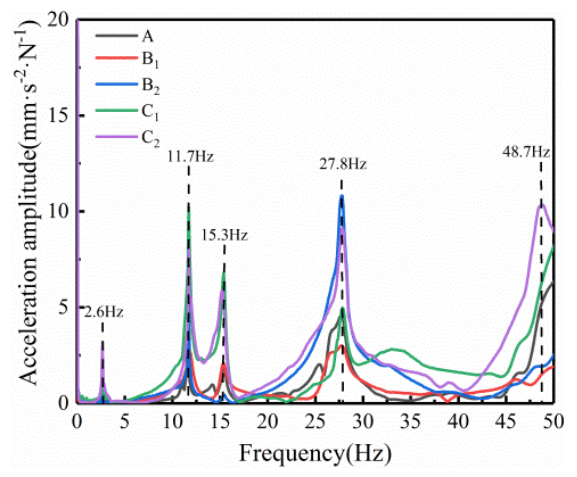

(c)

Figure 8. Spectral curve of different measuring points in sympodial branching ginkgo tree with (a) tree 4 , (b) tree 5 , and (c) tree 6 .

For the Y-shaped ginkgo trees, the acceleration amplitudes around $10 \mathrm{~Hz}$ in the vibration spectrum curve were all high. Trees 4 and 6 had acceleration peaks near $13 \mathrm{~Hz}$, while Tree 5 did not. The results show there was a natural frequency found in all three Y-shaped ginkgo trees at around $10 \mathrm{~Hz}$. Around $25 \mathrm{~Hz}$, the three Y-shaped test samples showed the largest acceleration amplitude in the $0-50 \mathrm{~Hz}$ spectrum curve. The peak frequencies were $23.7 \mathrm{~Hz}, 26.4 \mathrm{~Hz}, 27.8 \mathrm{~Hz}$. Near $50 \mathrm{~Hz}$, there was the last vibration frequency with a significant acceleration amplitude. However, the consistency of the acceleration amplitude of each measuring point around $50 \mathrm{~Hz}$ was low, and there were some points where the acceleration amplitude was not high at this frequency.

In general, the regularity of the vibration spectrum curve for Y-shaped fruit trees is very clear. In the $50 \mathrm{~Hz}$ range, there were about five resonance frequencies. The acceleration amplitude was high at the resonance frequency and low at the nonresonant frequency. Below the maximum acceleration amplitude, the vibration spectrum curve for each measuring point was consistent, decreasing only in the range of $30 \mathrm{~Hz} 50 \mathrm{~Hz}$. This means that based on vibration characteristics and resonance frequency between measuring points, Y-shaped ginkgo trees have much better vibration characteristics than monopodial ginkgo trees. Based on the frequency spectrum vibration test results, the vibration characteristics of the Y-shaped ginkgo trees are more likely to cause an overall strong response, having very consistent resonance frequency at different positions. According to the adaptability of organisms to the environment, trees avoid resonance in the natural environment to protect their branches from breaking. The structure of branches and leaves can also dissipate external excitation energy, such as wind vibration. However, the branch structure of artificially constructed Y-shaped ginkgo trees is much simpler than naturally growing ginkgo trees. 
This simple branching structure results in more consistent overall vibration characteristics and is more suitable for mechanical vibration harvesting.

\subsection{Simulation Analysis}

The modal analysis module in ANSYS was used to calculate the natural frequencies of the sample fruit trees. From the vibration theory, the natural frequency of bending of the beam structure in two orthogonal directions, perpendicular to the axial plane, is very close because the cross-section is a standard circle. So, the natural frequency exhibited a pattern where two adjacent orders were consistent and appeared in pairs, in the finite element calculation results. This study selects the natural frequency in the X-direction in the simulation results as the final calculation result, because this direction is consistent with the experimental excitation direction. There would be a disparity between the first calculation and actual measurements, due to differences between the model and the actual fruit tree, and between the simulation setting and the actual tree conditions. To improve the accuracy of the calculation results, we used the method proposed by Sellier [33] to adjust the fruit tree calculation model. The comparison between the adjusted calculation results of the natural frequency and the test results is shown in Table 4.

Table 4. Comparison of natural frequency between simulation and test.

\begin{tabular}{cccccc}
\hline & Monopodial Branching & & \multicolumn{3}{c}{ Y-Shaped Sympodial Branching } \\
\hline Simulation/Hz & Measure/Hz & Relative Error & Simulation/Hz & Measure/Hz & Relative Error \\
\hline 3.5 & 3.6 & $2.8 \%$ & 2.3 & 2.3 & 0.1 \\
15.7 & 15.9 & $1.6 \%$ & 10.1 & 13.1 & $0 \%$ \\
27.2 & 27.3 & $0.4 \%$ & 24.5 & 23.7 & $10.7 \%$ \\
33.4 & 34.2 & $2.3 \%$ & 48.4 & 47.0 & $3.4 \%$ \\
37.7 & 38.6 & $2.3 \%$ & & & \\
\hline
\end{tabular}

Only the frequencies where the test results are close to the finite element results are listed in the table. The number of natural frequencies calculated by finite element is much greater than the number actually measured; many frequencies with small acceleration amplitudes can be found in the test results and were not selected. Many branch vibrations at the far end of the canopy are nonlinear with low energy, and determining the natural frequency of these vibrations would be difficult. The linear finite element calculation model of tree vibration is different from the actual tree shape and growth environment. This could explain why the number of measurement results is less than the number of finite element calculations. The natural frequencies obtained from the calculations but not present in actual measurements are mainly concentrated in the low-frequency spectrum (i.e., below $15 \mathrm{~Hz}$ ). This is most likely due to the large number of natural frequencies concentrated in the low-frequency region. Many natural frequencies with low acceleration amplitudes in the spectrum curve are difficult to distinguish, especially when there are many natural frequencies in a very narrow frequency range.

Under the existing finite element model, the maximum relative error of the natural frequency calculation of the ginkgo tree vibration model was $10.7 \%$, and the median relative error was $2.3 \%$. The finite element model can be used to calculate the natural frequency with high accuracy. According to the simulation models, the response configurations vary for different crown type branches at different natural frequencies. In the vibration model of the monopodial branching tree (shown in Figure 9), all side branches vibrated slightly under the excitation of the main trunk at $3.5 \mathrm{~Hz}$. When the natural frequency was increased, the maximum vibration position appeared on the branches, and based on the mode shape, not all branches produced a large vibration response at the same time. In the two modes with high frequency, the maximum vibration position appeared at the end of the branches. 


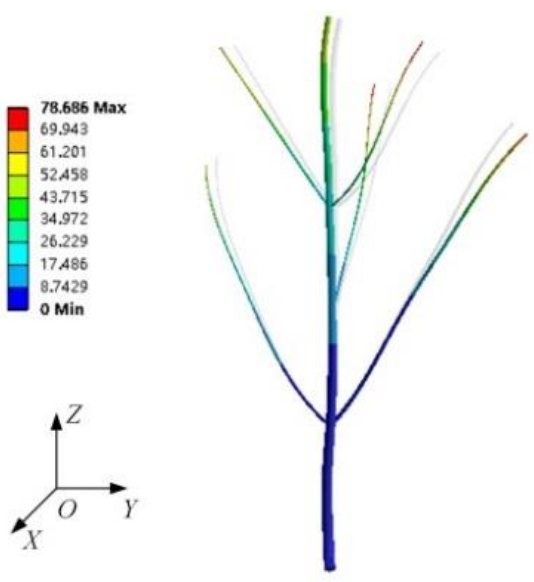

(a1)

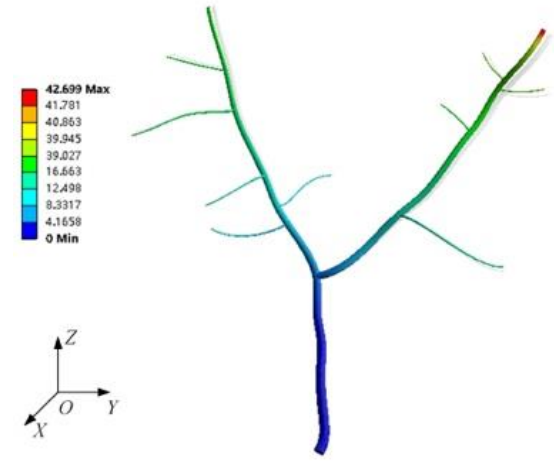

(b1)

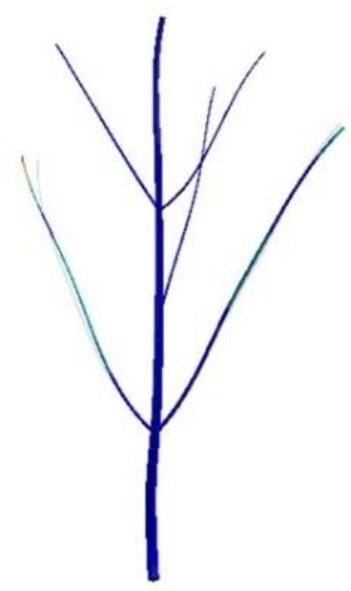

(a2)

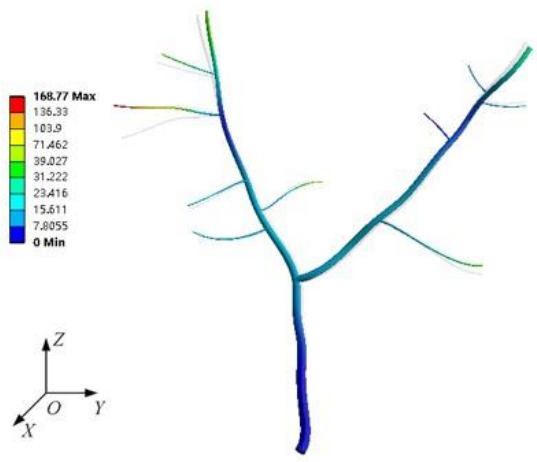

(b2)

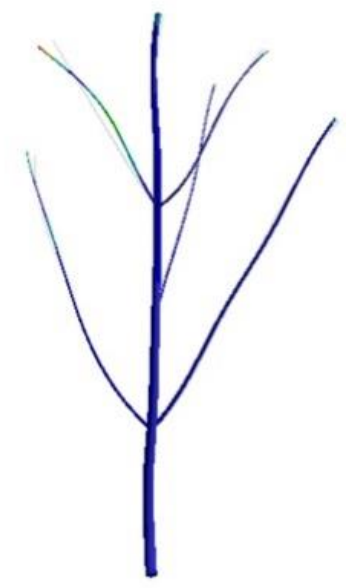

(a3)

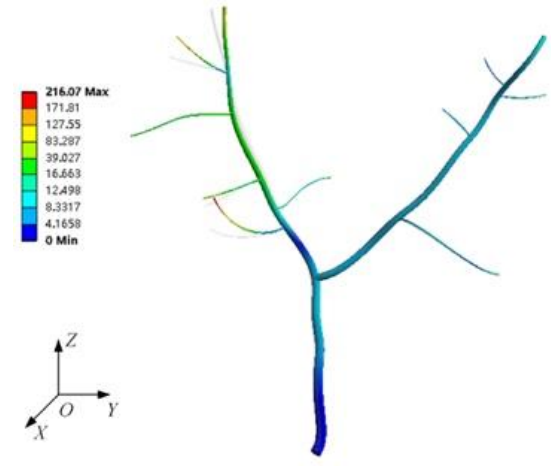

(b3)

Figure 9. Vibration models of monopodial branching tree 1 at (a1) $3.5 \mathrm{~Hz}$, (a2) $15.7 \mathrm{~Hz}$, and (a3) 33.4 Hz; Y-shaped sympodial branching tree 4 at (b1) $2.3 \mathrm{~Hz}$, (b2) $10.1 \mathrm{~Hz}$, and (b3) $24.5 \mathrm{~Hz}$.

Judging from the vibration shape in the Y-shaped sympodial branching in Figure 9, the maximum vibration was found at the end of the right branch. The Y-shaped tree did not show a heavy vibration at the fundamental frequency, unlike in the monopodial branching tree. This may be because the main trunk of the Y-shaped ginkgo tree was shorter, and had smaller influence on the vibrations. This vibration mode is different from the monopodial ginkgo tree, where the tree swings as a whole at the fundamental frequency. When the frequency was increased, the maximum vibration appeared at the end of a second branch. Compared with the branches of the monopodial ginkgo tree, the vibration in the two Y-shaped branches was also more powerful.

Based on the simulation results, the vibration model constructed by laser scanning was more similar to the real tree. The vibration mode calculated by the finite element method can be used to further characterize the tree's vibration characteristics. For the monopodial branching tree, there appeared a heavy vibration at the fundamental frequency, but the vibration at high frequency was mainly the local vibration at each branch. The vibration for Y-shaped sympodial branching was mainly concentrated on the two branches, and the maximum displacement occurred at the end of the secondary branches at high frequencies. At high frequencies, the overall vibration in Y-shaped ginkgo trees was better than in monopodial branching.

The finite element method was then used to calculate the natural frequency. Although some differences may be found between simulated and measured results, the simulation results are able to reflect the test results to a certain extent. Based on the relative error of the calculation results, the accuracy of the entity model constructed using laser scanning was higher compared to manual measurement and reconstruction. The model diagram obtained by simulation can more intuitively reflect the vibration state of the fruit tree. 
Combining the natural frequency analysis with the vibration model diagram provides better characterization and analysis of the vibrations at different natural frequencies, and field vibration harvesting frequency.

\subsection{Damping Coefficient}

Damping is an important structural dynamic characteristic that represents the dissipative effect of structure on energy. For vibration harvesting, small damping means less external excitation energy dissipation and helps improve the efficiency of vibration harvesting. There have been many studies on the damping characteristics of trees, but the trend of damping with frequency has not been considered. Studying the relationship between damping and frequency of trees can help select the vibration frequency with small damping, that would reduce energy consumption during vibration recovery. The damping ratio coefficient can be calculated by the method mentioned in 2.4 . This study analyzed the numerical magnitude and change law of the damping coefficient for multiorder natural frequencies of ginkgo trees with different crown structures. The mean of the calculated damping coefficients at different measuring points under the same frequency was used as the damping coefficient for the frequency. The damping coefficient test results are shown in Figure 10.

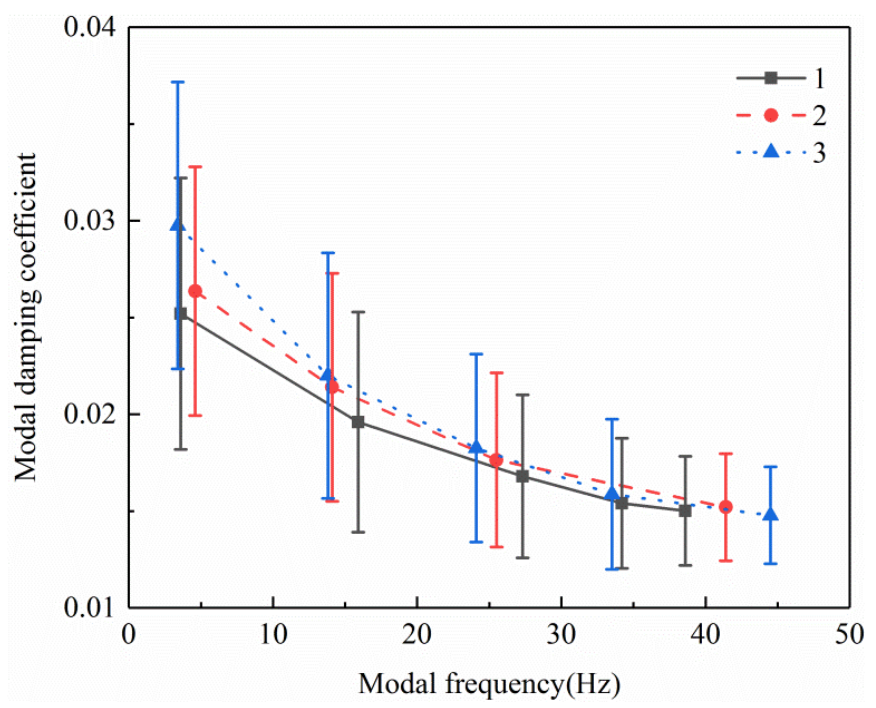

(a)

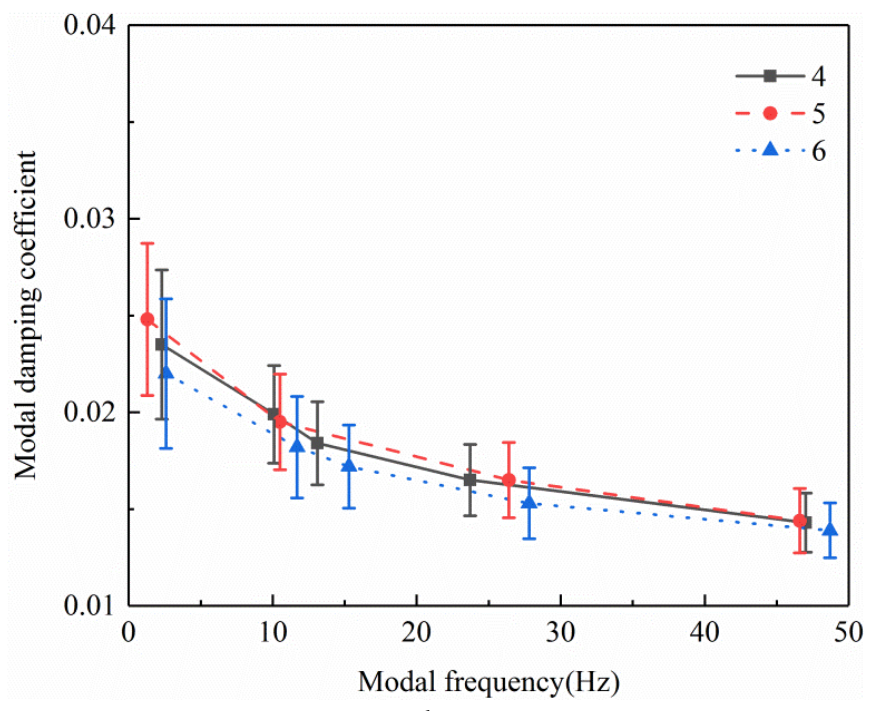

(b)

Figure 10. Modal damping coefficient with the (a) monopodial branching and (b) Y-shaped sympodial branching.

The modal damping coefficients for the different orders of the spectrum curves in each measurement point of the monopodial branching tree are presented in Figure 10a. The damping coefficients of the three test sample trees decreased as the natural frequency increased. There was little difference between the damping coefficients for test ginkgo trees with similar natural frequencies. The monopodial branching damping coefficient was 0.0148-0.0298. The fundamental frequency damping coefficients were between 0.025 and 0.03 , and gradually decreased to around 0.015 as the frequency was increased. This means that when trees vibrate at higher frequencies, the damping is small, and the energy dissipation is weak. The standard deviation of the fundamental frequency damping coefficient was between 0.00642 and 0.00741 , indicating that the damping coefficients at different test positions are comparatively different. The fundamental frequency damping coefficient of the main stem was greater than the coefficient of the side branches since damping is positively correlated with branch diameter. Since the trunk diameter is significantly larger than the side branches, the fundamental frequency damping in the trunk is greater than in the side branches. However, as the frequency increases, the damping coefficients at different measuring points tend to be similar because the error band is reduced. A smaller 
error band means that the damping at the main trunk decreases more rapidly as the natural frequency increases, compared to the decrease in the side branch damping coefficient. Above $30 \mathrm{~Hz}$, the damping coefficients were 38.9-50.3\% lower than the fundamental frequency and the standard deviation was 47.6-66.3\% lower than the fundamental frequency. Within the general excitation frequency of 10-25 Hz, the damping coefficient also dropped by $18.8-38.7 \%$ and the standard deviation dropped by $8.3-39.9 \%$. These results suggest that using an appropriate frequency to excite monopodial branching ginkgo trees can reduce energy dissipation in excitation.

The modal damping coefficients for the different orders of the spectrum curves in each measurement point of the Y-shaped sympodial branching tree are presented in Figure 10b. Similar to monopodial branching trees, the damping coefficients of the Y-shaped ginkgo tree decreased as the frequency increased. The sympodial branching damping coefficient was 0.0139-0.0248. At fundamental frequencies, the damping coefficients for the three sample trees were not much different. The damping coefficients were between 0.02 and 0.025 , smaller than the damping coefficients for monopodial trees. The standard deviation of the fundamental frequency damping coefficient was between 0.00385 and 0.00393 . This difference may be due to the irregular branch growth in monopodial trees compared with the more regular branch development in Y-shaped trees. Irregular growth may cause branches in opposite directions to cancel out energy. Branches in monopodial trees also tend to collide during vibration, which dissipates energy. After $10 \mathrm{~Hz}$, the vibration damping coefficient in Y-shaped trees dropped to below 0.02, but the minimum damping coefficient after $40 \mathrm{~Hz}$ was only slightly less than 0.015 . The error band of the damping coefficient for Yshaped trees at different frequencies was smaller than in monopodial branching trees. This suggests that the vibration characteristics of Y-shaped sympodial trees with simple crown structures are more consistent. The damping coefficient after $30 \mathrm{~Hz}$ was about $36.8-41.9 \%$ lower than the fundamental frequency and the standard deviation was 57.5-63.6\% lower than the fundamental frequency. Within the general excitation frequency of $10-25 \mathrm{~Hz}$, the damping coefficient also dropped by $15.3-29.8 \%$ and the standard deviation dropped by $32.3-52.2 \%$.

In summary, the damping coefficient of ginkgo trees decreases as the natural frequency increases, regardless of crown structure. This means that for ginkgo trees in general, properly increasing the vibration frequency helps the tree vibrate more intensely, with less energy loss. However, the effectiveness and efficacy of vibrating can be significantly affected by the tree's crown structure. The damping coefficient in Y-shaped trees is slightly lower than in monopodial trees. The consistency of the vibration damping coefficients in Y-shaped crowns at different measuring points is also better than in monopodial branching trees. These suggest that the vibration characteristics of Y-shaped sympodial ginkgo trees are better in terms of vibration damping.

\section{Conclusions}

This study examined the spectral characteristics of ginkgo trees with typical crown shapes and analyzed the natural frequencies to better understand their vibration characteristics. The natural frequencies at different measuring points of the Y-shaped trees were found to have good consistency. For monopodial ginkgo trees, the spectrum curve has a strong natural frequency above $30 \mathrm{~Hz}$, which is the frequency with the maximum acceleration. The maximum acceleration frequency in Y-branch ginkgo trees can be found at 20-30 Hz, which is within the general excitation range of fruit trees. These findings suggest that ginkgo trees with Y-shaped crown structures have better vibration characteristics.

The solid finite element model constructed using laser scanning resulted in a maximum relative error of $10.7 \%$ and a median error of $2.3 \%$. For monopodial ginkgo trees, the overall vibration was better at the fundamental frequency, and the local branch vibration was generally strong at high frequency vibrations. For Y-shaped ginkgo trees, the two primary branches vibrated strongly in the model. The overall vibration response of Y-shaped 
ginkgo trees at high frequencies was relatively uniform, and their vibration characteristics are better than the monopodial trees.

The damping coefficients decreased as the frequency increased, regardless of crown type. This suggests that high-frequency vibration harvesting could be used to reduce vibration energy dissipation. The damping coefficient in Y-shaped ginkgo trees was comparatively smaller than in the monopodial branching. When determining the excitation frequency to use, selecting the excitation frequency after $20 \mathrm{~Hz}$ would be beneficial to the overall vibration response of the ginkgo tree.

To improve vibration harvesting efficiency, the ginkgo tree's crown structure can be controlled during planting. In this study, due to constraints from the size of the indoor test space, the vibration tests were carried out using medium-sized ginkgo trees. More field experiments are needed to verify if the conclusions of this study would also be applicable to large-sized ginkgo trees. In future research, it is necessary to conduct experiments on the actual response of fruit trees under different frequency excitations to verify the effect of frequency on vibration harvesting, and through the actual vibration test, explore the impact of damping characteristics on the actual vibration of fruit trees.

Author Contributions: Conceptualization, Y.X. and L.X.; methodology, J.Z.; software, G.L.; validation, J.Z.; formal analysis, G.L.; investigation, J.Z.; resources, G.L.; data curation, Y.X.; writingoriginal draft preparation, Y.X.; writing—review and editing, L.X.; visualization, G.L.; supervision, L.X.; project administration, L.X.; funding acquisition, L.X. All authors have read and agreed to the published version of the manuscript.

Funding: This research was funded by National Key Research and Development Program of China, grant number 2016YFD0701501, and Postgraduate Research \& Practice Innovation Program of Jiangsu Province, grant number KYCX17_0862.

Institutional Review Board Statement: Not applicable.

Informed Consent Statement: Not applicable.

Data Availability Statement: The data presented in this study are available on request from the corresponding author. The data are not publicly available due to privacy.

Conflicts of Interest: The authors declare no conflict of interest. The funders had no role in the design of the study; in the collection, analyses, or interpretation of data; in the writing of the manuscript, or in the decision to publish the results.

\section{References}

1. Tian, F.; Chen, W.L.; Wu, C.E.; Kou, X.H.; Fan, G.J.; Li, T.T.; Wu, Z.H. Preservation of ginkgo (Ginkgo biloba L.) seeds by coating with chitosan/nano- $\mathrm{TiO}_{2}$ and chitosan/nano-SiO 2 films. Int. J. Biol. Macromol. 2018, 126, 917-925. [CrossRef] [PubMed]

2. Wang, H.Y.; Zhang, Y.Q. The main active constituents and detoxification process of Ginkgo biloba seeds and their potential use in functional health foods. J. Food Compos. Anal. 2019, 83, 103247. [CrossRef]

3. Zhou, G.; Yao, X.; Tang, Y.; Qian, D.; Su, S.; Zhang, L.; Qin, Y. An optimized ultrasound-assisted extraction and simultaneous quantification of 26 characteristic components with four structure types in functional foods from ginkgo seeds. Food Chem. 2014, 158, 177-185. [CrossRef] [PubMed]

4. Guo, Y.; Guo, J.; Shen, X.; Wang, G.; Wang, T. Predicting the Bioclimatic Habitat Suitability of Ginkgo biloba L. in China with Field-Test Validations. Forests 2019, 10, 705. [CrossRef]

5. Zhou, Q.; Mu, K.; Xu, M.; Ma, X.; Ni, Z.; Wang, J.; Xu, L.-A. Variation in the Concentrations of Major Secondary Metabolites in Ginkgo Leaves from Different Geographical Populations. Forests 2017, 8, 266. [CrossRef]

6. National Forestry and Grassland Administration. China Forestry and Grassland Statistical Yearbook; China Forestry Press: Beijing, China, 2019.

7. Chen, X.Z. The development status and countermeasures of ginkgo industry in Taizhou. Mod. Agric. Technol. $2016,7,330-332$.

8. Li, Y.d. Analysis on Value of Ginkgo biloba and Its Industry Status. J. Chang. Univ. 2017, 27, 32-37.

9. Chen, D.; Du, X.Q.; Wang, S.M.; Zhang, Q. Mechanism of vibratory fruit harvest and review of current advance. Trans. Chin. Soc. Agric. Eng. 2011, 27, 195-200. [CrossRef]

10. Sanders, K.F. Orange Harvesting Systems Review. Biosyst. Eng. 2005, 90, 115-125. [CrossRef]

11. Zhou, J.; He, L.; Zhang, Q.; Du, X.; Chen, D.; Karkee, M. Evaluation of the influence of shaking frequency and duration in mechanical harvesting of sweet cherry. Appl. Eng. Agric. 2013, 29, 607-612. [CrossRef] 
12. Liu, Y.; Wang, H.H.; Liu, Y.; Yang, Y.T.; Wang, D.Z. Research Progress of Forest-fruit Mechanized Picking and Sorting. World For. Res. 2020, 33, 20-25.

13. Castro-Garcia, S.; Sola-Guirado, R.R.; Gil-Ribes, J.A. Vibration analysis of the fruit detachment process in late-season 'Valencia' orange with canopy shaker technology. Biosyst. Eng. 2018, 170, 130-137. [CrossRef]

14. Aragon-Rodriguez, F.; Castro-Garcia, S.; Sola-Guirado, R.R.; Rafael, R.; Gil-Ribes, J.A. Fruit abscission pattern of 'Valencia' orange with canopy shaker system. Sci. Hortic. 2019, 246, 916-920. [CrossRef]

15. Wang, W.Z.; Lu, H.Z.; Zhang, S.M.; Yang, Z. Damage caused by multiple impacts of litchi fruits during vibration harvesting. Comput. Electron. Agric. 2019, 162, 732-738. [CrossRef]

16. Zhou, J.; He, L.; Zhang, Q.; Karkee, M. Effect of excitation position of a handheld shaker on fruit removal efficiency and damage in mechanical harvesting of sweet cherry. Biosyst. Eng. 2014, 125, 36-44. [CrossRef]

17. Zhang, Z.; Igathinathane, C.; Li, J.; Cen, H.; Lu, Y.; Flores, P. Technology progress in mechanical harvest of fresh market apples. Comput. Electron. Agric. 2020, 175, 105606. [CrossRef]

18. Liu, T.H.; Luo, G.; Ehsani, R.; Toudeshki, A.; Zou, X.J.; Wang, H.J. Simulation study on the effects of tine-shaking frequency and penetrating depth on fruit detachment for citrus canopy-shaker harvesting. Comput. Electron. Agric. 2018, 148, 54-62. [CrossRef]

19. Kane, B.; Modarres, S.Y.; James, K.R.; Reiland, M. Effects of crown structure on the sway characteristics of large decurrent trees. Trees-Struct. Funct. 2014, 28, 151-159. [CrossRef]

20. Sellier, D.; Fourcaud, T. Crown structure and wood properties:influence on tree sway and response to high winds. Am. J. Bot. 2009, 96, 885-896. [CrossRef]

21. Buchacher, R.; Ledermann, T. Interregional Crown Width Models for Individual Trees Growing in Pure and Mixed Stands in Austria. Forests 2020, 11, 114. [CrossRef]

22. Castro-Garcia, S.; Blanco-Roldan, G.L.; Gil-Ribes, J.A.; Aguera-Vega, J. Dynamic analysis of olive trees in intensive orchards under forced vibration. Trees-Struct. Funct. 2008, 22, 795-802. [CrossRef]

23. Jiménez-Jiménez, F.; Castro-García, S.; Blanco-Roldan, G.L.; Ferguson, L.; Rosa, U.A.; Gil-Ribes, J.A. Table olive cultivar susceptibility to impact bruising. Postharvest Biol. Technol. 2013, 86, 100-106. [CrossRef]

24. Shamshiri, R.; Ehsani, R.; Maja, J.M.; Roka, F.M. Determining machine efficiency parameters for a citrus canopy shaker using yield monitor data. Appl. Eng. Agric. 2013, 29, 33-41. [CrossRef]

25. Wang, C.Q.; Xu, L.Y.; Zhou, H.P.; Cui, Y.M.; Cui, H. Development and experiment of eccentric-type vibratory harvester for forest-fruits. Trans. Chin. Soc. Agric. Eng. 2012, 28, 10-16. [CrossRef]

26. Lin, H.; Xu, L.Y.; Zhou, H.P.; Xuan, Y.; Jia, Z.C.; Chen, Q. Relationship between frequency spectrum characteristics and vibration responses of Ginkgo biloba trees during mechanical harvesting operation. Trans. Chin. Soc. Agric. Eng. 2017, 33, 51-57. [CrossRef]

27. Xu, L.Y.; Liu, G.H.; Xuan, Y.; Zhou, J. Mathematical model of fruit's aerial movement in vibration response. Trans. Chin. Soc. Agric. Eng. 2019, 35, 206-213. [CrossRef]

28. He, L.Y.; Liu, X.C.; Du, X.Q.; Wu, C.Y. In-situ identification of shaking frequency for adaptive vibratory fruit harvesting. Comput. Electron. Agric. 2020, 170, 105245. [CrossRef]

29. Xuan, Y.; Xu, L.Y.; Liu, G.H.; Zhou, J. The vibrational response of simulated Ginkgo biloba fruit based on their frequency spectrum characteristics. PLoS ONE 2020, 15, 0235494. [CrossRef]

30. Bentaher, H.; Haddar, M.; Fakhfakh, T.; Mâalej, A. Finite elements modeling of olive tree mechanical harvesting using different shakers. Trees 2013, 27, 1537-1545. [CrossRef]

31. Tinoco, H.A.; Ocampo, D.A.; Peña, F.M.; Sanz-Uribe, J.R. Finite element modal analysis of the fruit-peduncle of Coffea arabica L. var. Colombia estimating its geometrical and mechanical properties. Comput. Electron. Agric. 2014, 108, 17-27. [CrossRef]

32. Jackson, T.; Shenkin, A.; Wellpott, A.; Calders, K.; Origo, N.; Disney, M.; Burt, A.; Raumonen, P.; Gardiner, B.; Herold, M.; et al. Finite element analysis of trees in the wind based on terrestrial laser scanning data. Agric. For. Meteorol. 2019, 265, 137-144. [CrossRef]

33. Xu, L.Y.; Liu, G.H.; Zhou, J.; Zhou, H.P.; Jiang, X.S.; Xuan, Y. Construction of the vibration model of the fruit trees with fruits and leaves for vibration harvesting. Trans. Chin. Soc. Agric. Eng. 2020, 36, 1-12. [CrossRef]

34. Wang, D.; Chen, D.; Wang, S.M.; Chen, Z.; Zhang, F. Analysis on vibratory harvesting mechanism for trained fruit tree based on finite element method. Trans. Chin. Soc. Agric. Eng. 2017, 33, 56-62. [CrossRef]

35. Spatz, H.C.; Theckes, B. Oscillation damping in trees. Plant Sci. Int. J. Exp. Plant Biol. 2013, 207, 66-71. [CrossRef]

36. Du, X.Q.; Wu, C.Y.; He, L.Y.; Tong, J.H. Dynamic characteristics of dwarf Chinese hickory trees under impact excitations for mechanical fruit harvesting. Int. J. Agric. Biol. Eng. 2015, 8, 17-25. [CrossRef]

37. Jonsson, M.J.; Foetzki, A.; Kalberer, M.; Lundstro, T.; Ammann, W.; Stockli, V. Natural frequencies and damping ratios of Norway spruce (Picea abies (L.) Karst) growing on subalpine forested slopes. Trees 2007, 21, 541-548. [CrossRef]

38. Sellier, D.; Fourcaud, T.; Lac, P. A finite element model for investigating effects of aerial architecture on tree oscillations. Tree Physiol. 2006, 26, 799-806. [CrossRef]

39. Wood, C.J.; Neild, S.A. Estimating stem and root-anchorage flexibility in trees. Tree Physiol. 1999, 19, 141-151. [CrossRef]

40. San, Y.L.; Yang, H.M.; Wang, X.N.; Niu, C.H.; Guo, W.S.; Hou, S.L. Effects of vibration mode and frequency on vibration harvesting of apricot trees. Trans. Chin. Soc. Agric. Eng. 2018, 34, 10-17. [CrossRef]

41. De Langre, E. Plant vibrations at all scales: A review. J. Exp. Bot. 2019, 70, 3521-3531. [CrossRef] 